\title{
A Evolução de um Pianismo Eclético: Gilberto Mendes e o Uso da Citação Musical
}

\author{
MÁRCIO BEZERRA
}

\section{Introdução}

O nome de Gilberto Mendes (n. 1922) tornou-se público nos anos 60 , período em que ele esteve ligado ao Grupo Música Nova. Naquela época, a produção do compositor refletiria o seu engajamento com um projeto de renovação da linguagem musical; a sua interação com os poetas concretos o consagraria (ainda que de modo pouco ortodoxo) como um dos expoentes da literatura para conjuntos corais deste século. $\mathrm{Na}$ década de 80, Gilberto Mendes surpreendeu tanto seus defensores quantos seus críticos mais contundentes ao abandonar o experimentalismo radical, voltando sua atenção para a música instrumental. Sem dúvida, naquela altura todos desconheciam sua capacidade para "escrever música", no sentido mais convencional do termo.

A recente redescoberta das obras de juventude do compositor (canções e peças para piano, na sua maioria) tem-nos permitido compreender de maneira mais precisa sua trajetória criativa e, ao mesmo tempo, reavaliar sua contribuição para a música contemporânea. Após os recitais de José Eduardo Martins no XXVII Festival Música Nova (1991), a defesa de duas teses universitárias e o surgimento de diversas gravações nos últimos anos, a obra pianística de Gilberto Mendes deixou de ser considerada como um item secundário e tem sido estudada como parte fundamental da sua produção.

Este artigo analisa duas das principais peças para piano do compositor santista: o Allegro da Sonatina Mozartiana (1951) e Vento Noroeste (1982). A seleção de obras de fases tão distintas tem como 
principal meta distinguir procedimentos composicionais recorrentes - os quais são responsáveis pela definição de um estilo pessoal -, além de traçar o amadurecimento na manipulação de uma técnica que distingue particularmente o compositor: a citação musical.

Em parte, as análises das referidas peças foram previamente apresentadas em minha tese doutoral A Unique Brazilian Composer: A Study of the Music of Gilberto Mendes Through Selected Piano Pieces (University of Arizona, 1998). Na conclusão deste artigo, proponho uma confrontação inédita entre as duas obras, com o intuito de aprofundar a discussão sobre a evolução técnica e estética do repertório pianístico do Gilberto Mendes, inserindo-o no contexto mais amplo da sua criação musical.

\section{Sonatina Mozartiana}

A Sonatina Mozartiana constitui o primeiro ensaio de Gilberto Mendes na grande forma e o seu movimento inicial, Allegro, pode ser considerado como o ponto culminante da fase de formação do compositor. Caracterizada pelo autodidatismo e por uma certa solidão artística - já que as peças desse período permaneceriam inéditas por muitas décadas -, podemos observar nesta fase uma aderência superficial à estética nacionalista, motivada, sobretudo, por razões ideológicas. Já no que concerne aos aspectos técnicos, as obras desse período prenunciam a originalidade dos processos composicionais de Gilberto Mendes, graças, sobretudo, ao uso da citação musical.

Combinando elementos nacionalistas dentro de um esquema formal que segue à risca o Allegro da Sonata em Dó Maior, K.545, de Mozart, o primeiro movimento da Sonatina Mozartiana é uma paródia bem-humorada, onde cada passo dado pelo compositor austríaco é seguido. $\mathrm{O}$ primeiro tema do movimento tem desenho melódico bastante similar ao do modelo original; apenas o baixo de Alberti é substituído por um acompanhamento sincopado que, combinado com o caráter modal da melodia, confere à obra um certo clima brasileiro (exemplos 1 e 2). 
Exemplo 1. Wolfgang Amadeus Mozart - Sonata em Dó Maior, K.545: $1^{\circ}$ tema (compassos 1-4).

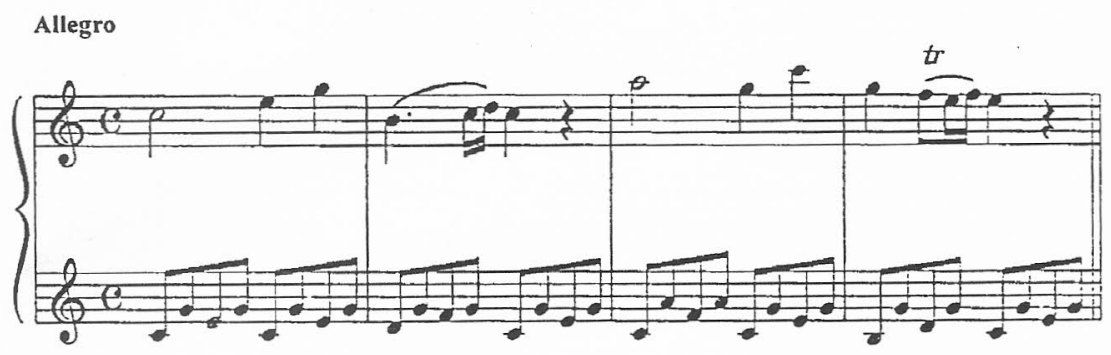

Exemplo 2. Gilberto Mendes - Sonatina Mozartiana: $1^{\circ}$ tema (compassos 1-4).

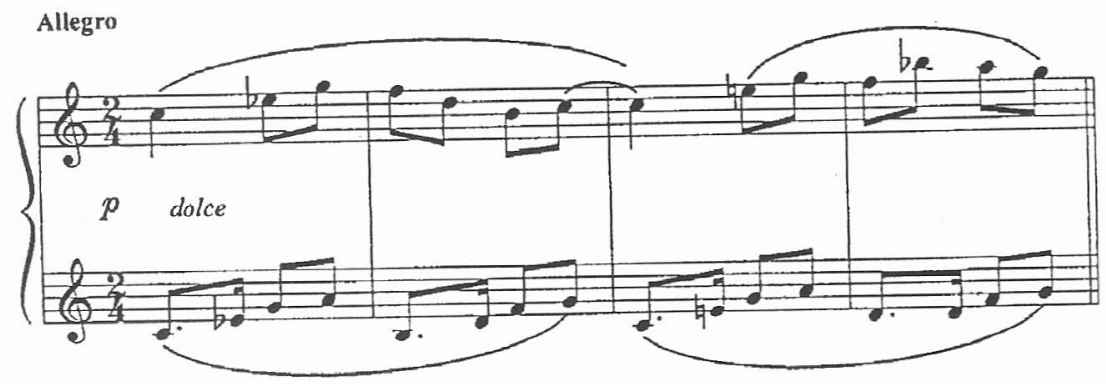

A ponte para o segundo tema recebe tratamento similar, mas na Sonatina as escalas são escritas para as duas mãos, em intervalo de sextas paralelas. Estas, ao invés de conduzirem diretamente à cadência, tomam um curioso desvio em ritmo de tango brasileiro (exemplos 3 e 4).

Exemplo 3. Wolfgang Amadeus Mozart - Sonata em Dó Maior, K.545: ponte para o $2^{\circ}$ tema (compassos 5-6).

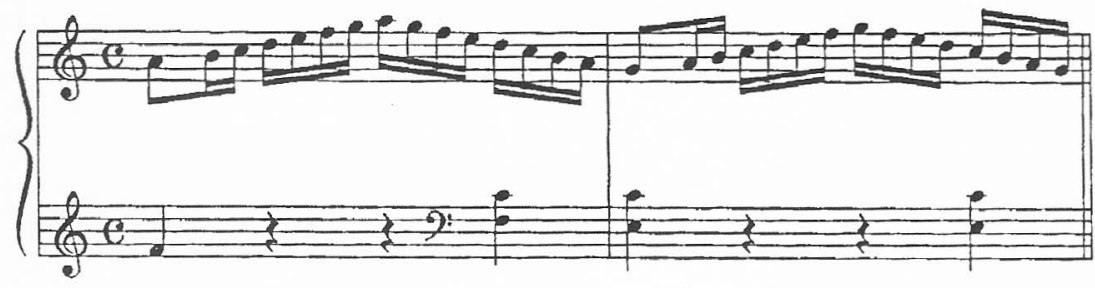


Exemplo 4. Gilberto Mendes - Sonatina Mozartiana: ponte para o $2^{\circ}$ tema (compas$\operatorname{sos} 11-14)$.

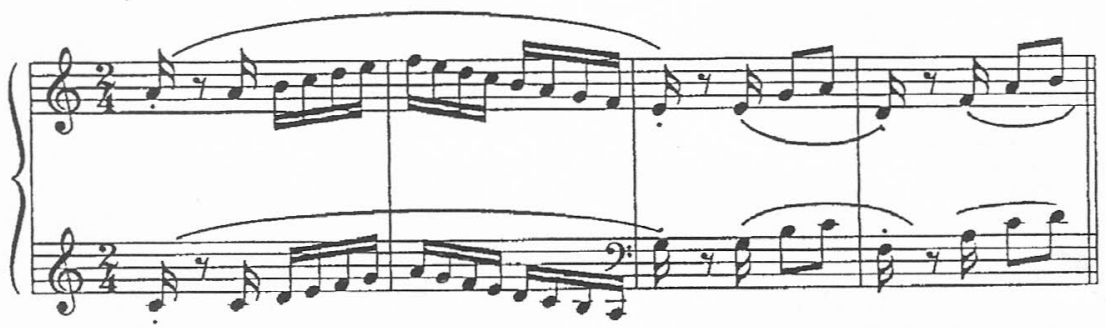

A figuração que introduz o segundo tema é temperada com as típicas síncopes (exemplos 5 e 6). Este novo tema recebe tratamento similar ao do primeiro - acompanhamento sincopado e melodia com inflexão modal (exemplos 7 e 8 na página seguinte).

Exemplo 5. Wolfgang Amadeus Mozart - Sonata em Dó Maior, K.545: introdução ao $2^{\circ}$ tema (compasso 13 ).

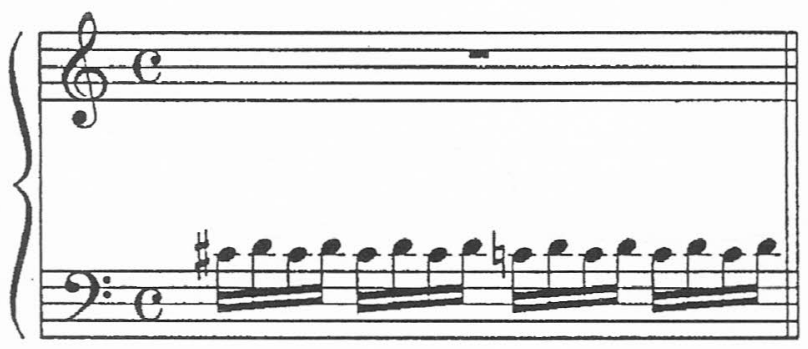

Exemplo 6. Gilberto Mendes - Sonatina Mozartiana: introdução ao $2^{\circ}$ tema (compas$\operatorname{sos} 22-23)$.

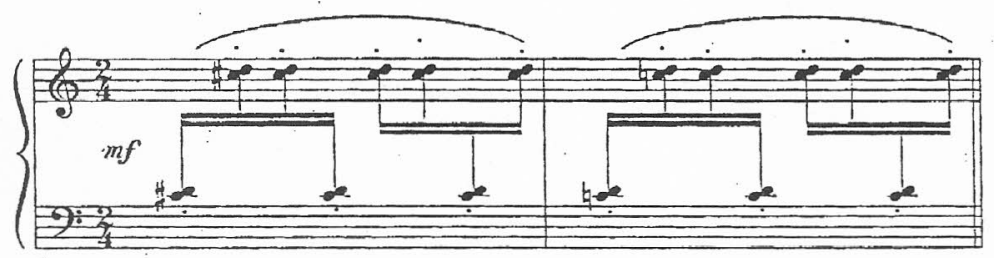


Exemplo 7. Wolfgang Amadeus Mozart - Sonata em Dó Maior, K.545: $2^{\circ}$ tema (compassos 14-15).

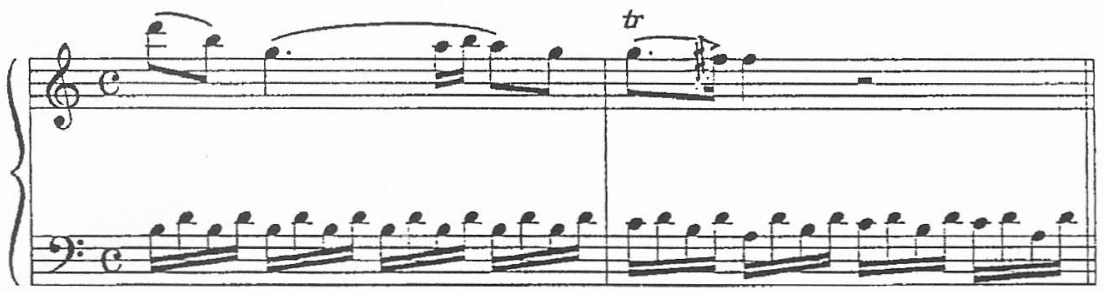

Exemplo 8. Gilberto Mendes - Sonatina Mozartiana: $2^{\circ}$ tema (compassos 26-29).

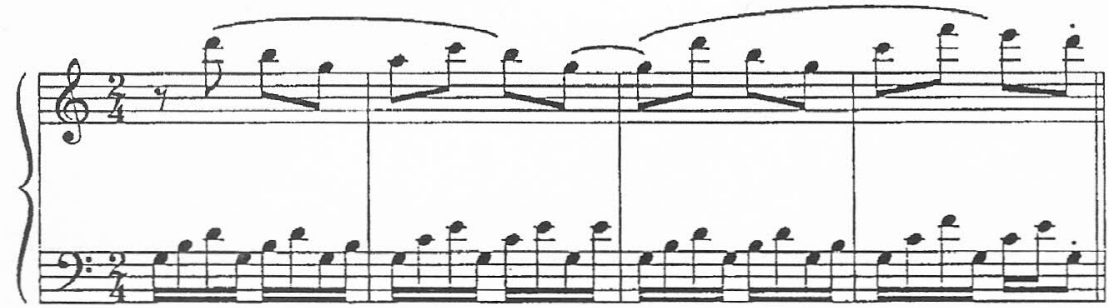

O paralelismo com o modelo mozartiano tem continuação no desenvolvimento, onde a seqüência em mãos alternadas também é reproduzida, uma vez mais com as características síncopes (exemplos 9 e 10).

Exemplo 9. Wolfgang Amadeus Mozart - Sonata em Dó Maior, K.545: seqüência (compassos 36-38).

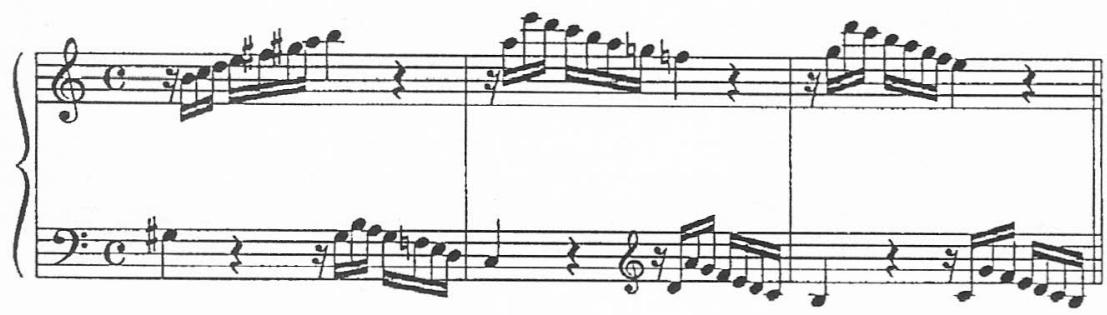


Exemplo 10. Gilberto Mendes: Sonatina Mozartiana: seqüência (compassos 58$61)$.

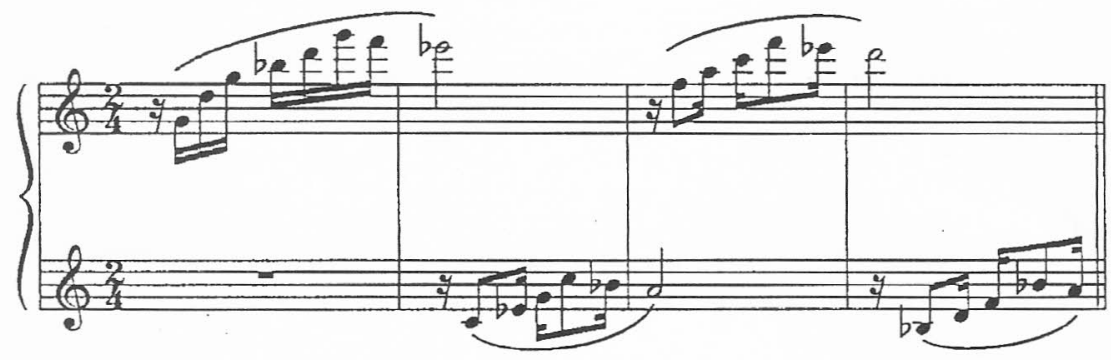

Precedendo a recapitulação, Mendes insere uma inesperada citação da Invenção em Lá Menor, BWV 784, de Bach (exemplos 11 e 12). Na coda, uma figuração sincopada é repetida diversas vezes, concluindo o movimento em clima de bom humor (exemplo 13).

Exemplo 11. Johann Sebastian Bach - Invenção em Lá Maior, BWV 784 (compas$\operatorname{sos} 1-2)$.

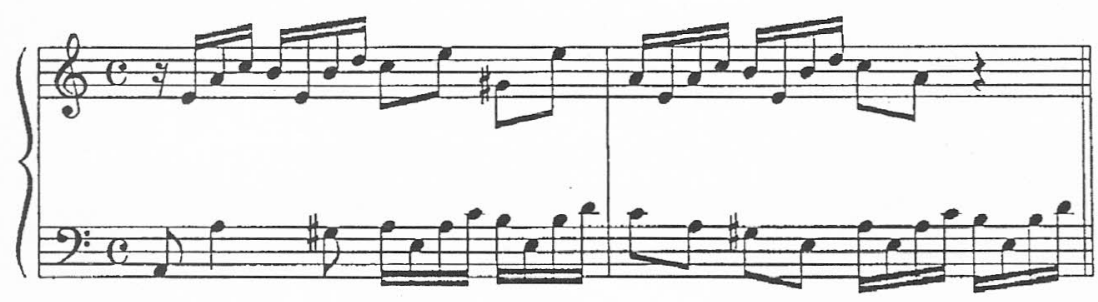

Exemplo 12. Gilberto Mendes - Sonatina Mozartiana: ponte para a recapitulação (compassos 90-93).

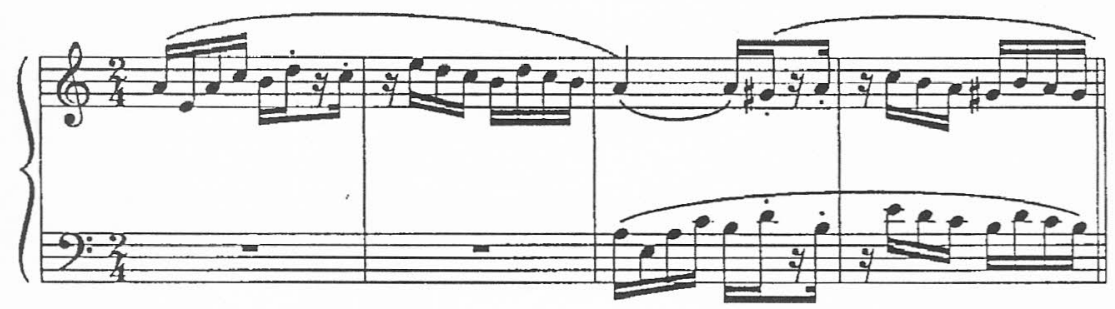


Exemplo 13. Gilberto Mendes - Sonatina Mozartiana: coda (compassos 150-153).

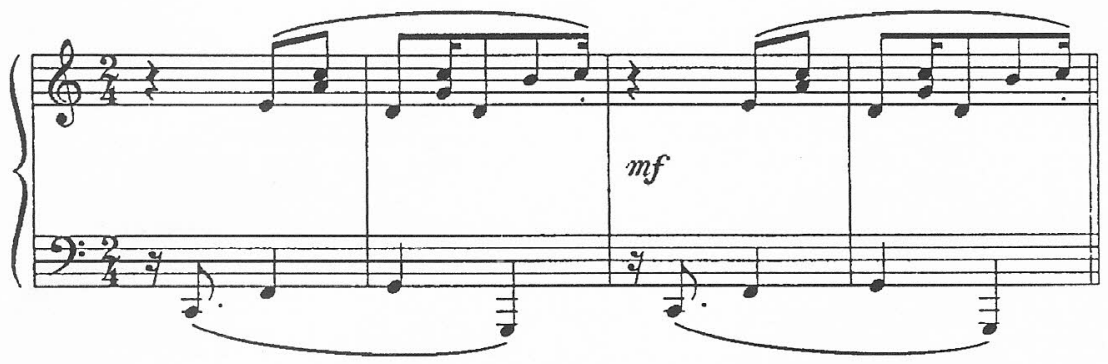

Apesar de se constituir claramente em "ensaio de estudante", este primeiro movimento da Sonatina já apresenta diversas características comuns às da maturidade de Gilberto Mendes. Entre elas, a preferência por linhas melódicas ascendentes, a presença de passagens repetitivas não-direcionais e o uso da citação musical como ferramenta fundamental do processo criativo. Este último elemento, por ser o responsável pelo caráter singular da obra do compositor, merece ser analisado mais detalhadamente.

O primeiro experimento de Gilberto Mendes com citação musical ocorreu em 1947, na Canção da Rússia (Pequeno Álbum para Crianças). Nesta miniatura para piano, que tem como modelo o Prelúdio Op. $28 n^{0} 6$ de Chopin, já podemos observar uma característica comum às citações em obras posteriores: as peças escolhidas como modelo pertencem, em sua grande maioria, ao repertório do instrumento para o qual a nova obra está sendo escrita. Também típico é o fato de que, mesmo nas citações visualmente mais exatas, a fonte original é pouco audível, já que só a textura e a estrutura rítmica originais são reproduzidas, recebendo as alturas sempre alterações substanciais ${ }^{1}$.

Inicialmente, este uso de "modelos" em algumas obras tinha uma razão prática: o repertório básico constituía o único guia a ser usado

1. Como podemos observar, o uso do termo citação é pouco apropriado no caso da música de Gilberto Mendes. O próprio compositor já me expressou a sua preferência por paronomásia, que tampouco é expressão completamente oportuna. Paródia, no sentido utilizado pela música da renascença, seria a nomenclatura que mais se aproximaria; porém, devido às outras conotações que apresenta, descarto-a em favor de citação, embora consciente de suas limitações. 
pelo jovem autodidata nas suas incursões criativas. Muito provavelmente, ele ignorava o ineditismo e a originalidade desta maneira de escrever. $\mathrm{Na}$ verdade, no seu isolamento artístico, Gilberto Mendes estava forjando as bases de uma linguagem musical própria, completamente alheia às querelas ideológicas entre nacionalistas e cosmopolitistas, tão características daquele período. As reações não tardariam a se manifestar.

Apesar de a Sonatina Mozartiana ter permanecido inédita até a sua redescoberta pelo pianista e musicólogo José Eduardo Martins (a quem foi tardiamente dedicada) nos anos oitenta, o compositor tentou divulgála no pequeno círculo de músicos - ligados em sua maioria ao Partido Comunista - ao qual tinha acesso. Uma das poucas pessoas a examinar a Sonatina (além de algumas das Peças para Piano) na época da sua composição foi a pianista Anna Stella Schic, que, segundo o compositor: "desaprovou solenemente (ela era comunista, por essa época) o meu decadentismo cosmopolita; saí de sua casa com a sensação de ter sido reprovado com nota zero" . O motivo para tal condenação é de fácil compreensão: os procedimetnos técnicos pouco convencionais, o ecletismo das fontes de inspiração e, principalmente, o uso exagerado de síncopes em diversas passagens, conferem à Sonatina Mozartiana uma qualidade irônica, que a transforma não só em uma paródia de Mozart, mas do nacionalismo brasileiro em geral. A pianista parece ter captado nesta ironia um sintoma da falta de afinidade musical do compositor com a estética nacionalista, da qual, de fato, desligar-se-ia ele em breve.

\section{Vento Noroeste}

Ao contrário da Sonatina Mozartiana, Vento Noroeste foi composta quando Gilberto Mendes já havia adquirido notoriedade no cenário musical internacional. No Brasil, seu nome ainda estava ligado às vanguardas mais radicais e ao experimentalismo de composições como Cidade (1964), Vai e Vem (1969) e Santos Football Music (1969). Vento Noroeste - peça típica da fase atual do compositor, ca-

2. Gilberto Mendes, Uma Odisséia Musical: dos Mares do Sul à Elegância Pop/ Art Déco, São Paulo, Editora da Universidade de São Paulo e Editora Giordano, 1994, p. 53. 
racterizada pelo retorno à música instrumental - foi sua primeira obra para piano após um hiato de vinte anos (a peça anterior foi Música para Piano $n^{\circ} 1$ de 1962).

Até o presente, Vento Noroeste é o mais complexo exemplar do repertório pianístico de Gilberto Mendes. Nesta obra, dedicada ao pianista Caio Pagano, o compositor utiliza, de maneira brilhante, muitos dos elementos presentes em peças de fases anteriores, principalmente o uso de passagens repetitivas (denotando, agora, influência do minimalismo), preferência por temas melódicos ascendentes e uso persistente de citações musicais. Em Vento Noroeste, os fragmentos utilizados pelo compositor são tirados do repertório pianístico romântico, particularmente dos Estudos e Prelúdios de Chopin. Embora haja um grande número de citações, elas são integradas à obra através do uso de agregados de doze tons, distribuídos dentro duma estrutura formal bem delineada.

Entre os principais motivos de Vento Noroeste, dois são baseados em citações (motivos I e III). Ambos são derivados de peças de Chopin: o primeiro, do Estudo Op. $25 \mathrm{n}^{\circ} 6$ (exemplos 14 e 15), enquanto o segundo é baseado no Estudo Op. $25 \mathrm{n}^{\circ} 1$ (exemplos 16 e 17).

Exemplo 14. Frédéric Chopin - Estudo Op. $25 \mathrm{n}^{\circ} 6$ (compassos 1-3).

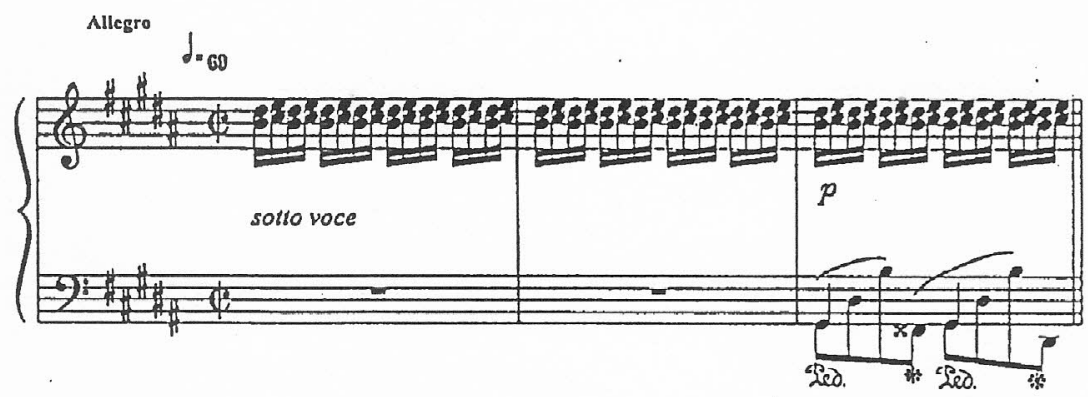


Exemplo 15. Gilberto Mendes - Vento Noroeste: motivo I (página 2) ${ }^{3}$

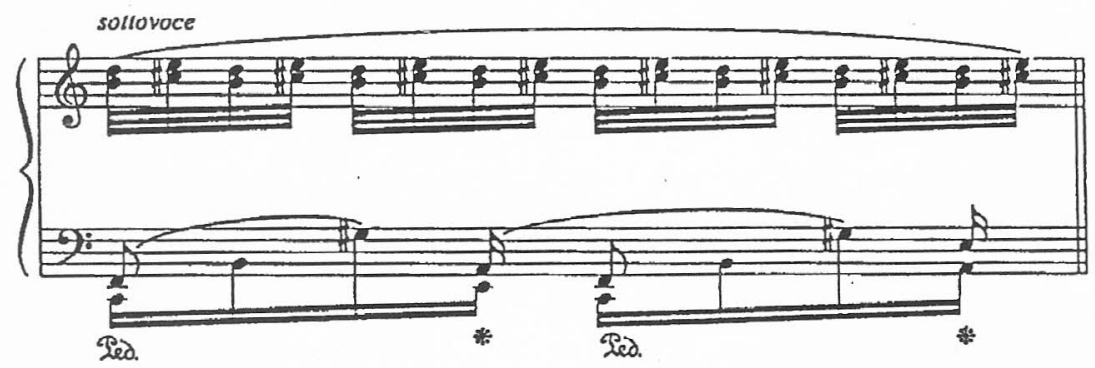

Exemplo 16. Frédéric Chopin - Estudo Op. $25 \mathrm{n}^{\circ} 1$ (compassos 1-2).

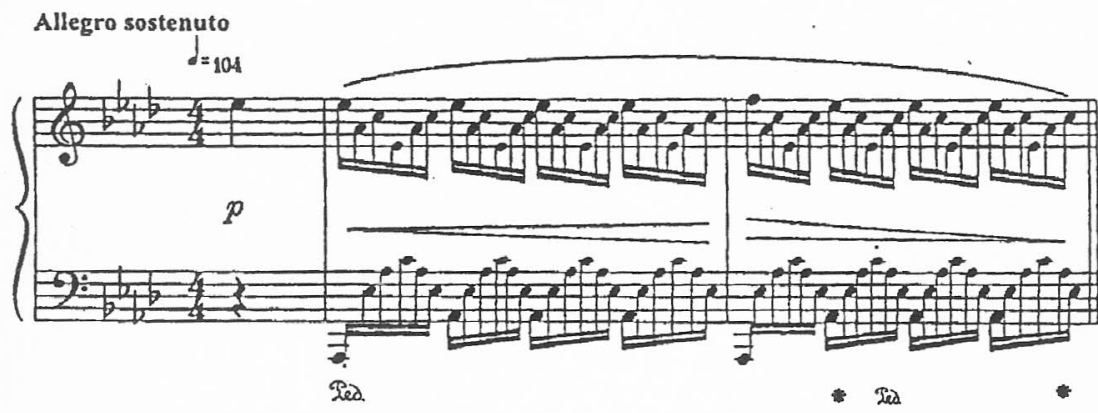

Exemplo 17. Gilberto Mendes - Vento Noroeste: motivo III (página 11).

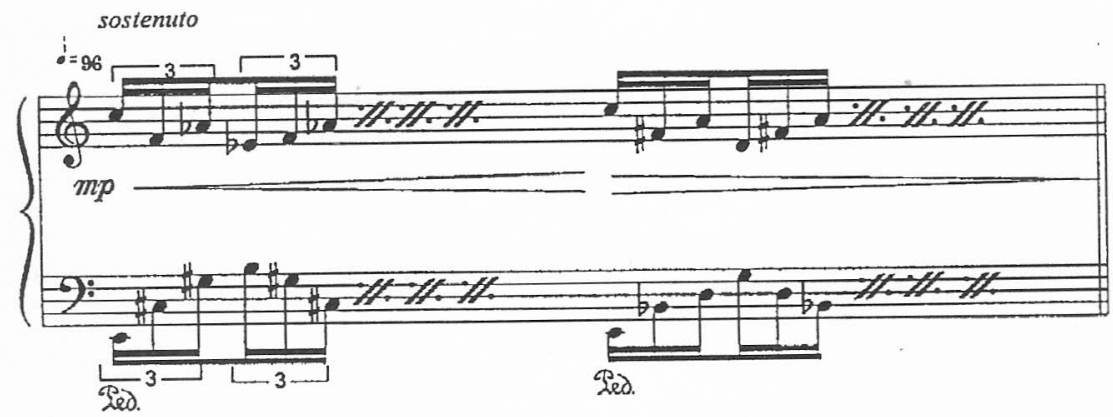

3. Na falta de compassos, indicamos o número das páginas dos exemplos musicais de Vento Noroeste (aqui apresentada na versão revisada de 1984). 
Alguns dos motivos secundários também são baseados em peças de Chopin, mais especificamente nos Prelúdios Op. 28 nos 8 e 5 (exemplos 18 a 21).

Exemplo 18. Frédéric Chopin - Prelúdio Op. 28 n 8 (compasso 1).

Molto agitato

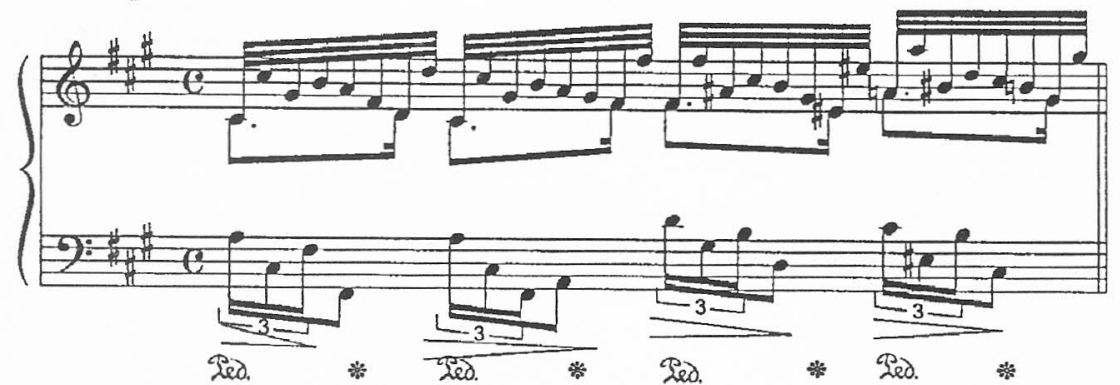

Exemplo 19: Gilberto Mendes - Vento Noroeste: motivo secundário (página 11). molto agitato

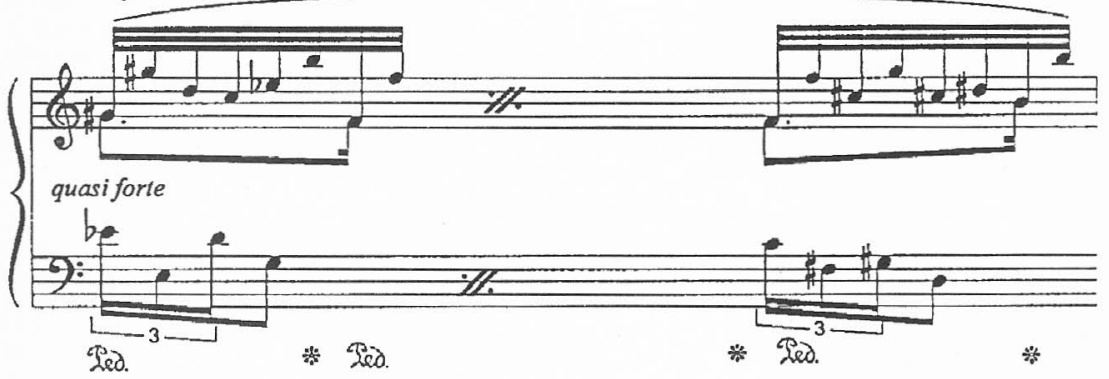

Exemplo 20. Frédéric Chopin - Prelúdio Op. 28 n 5 (compassos 1-4).

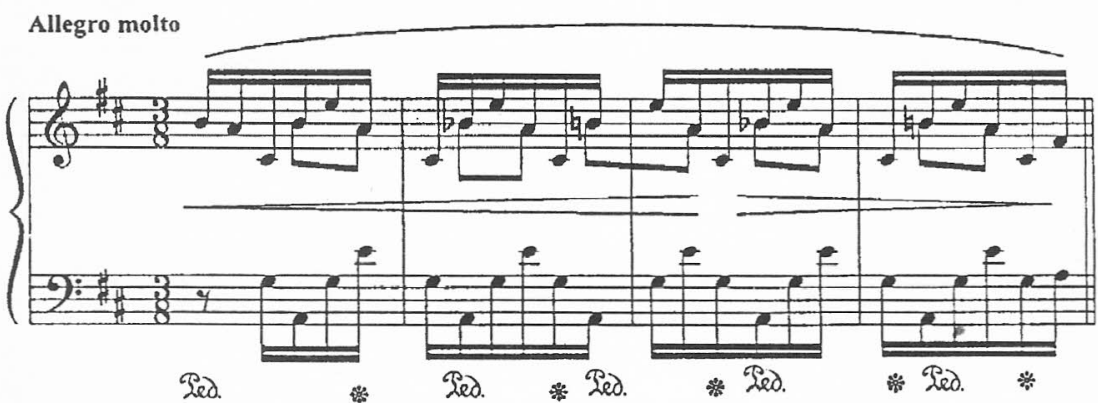


Exemplo 21. Gilberto Mendes - Vento Noroeste: motivo secundário (página 14).

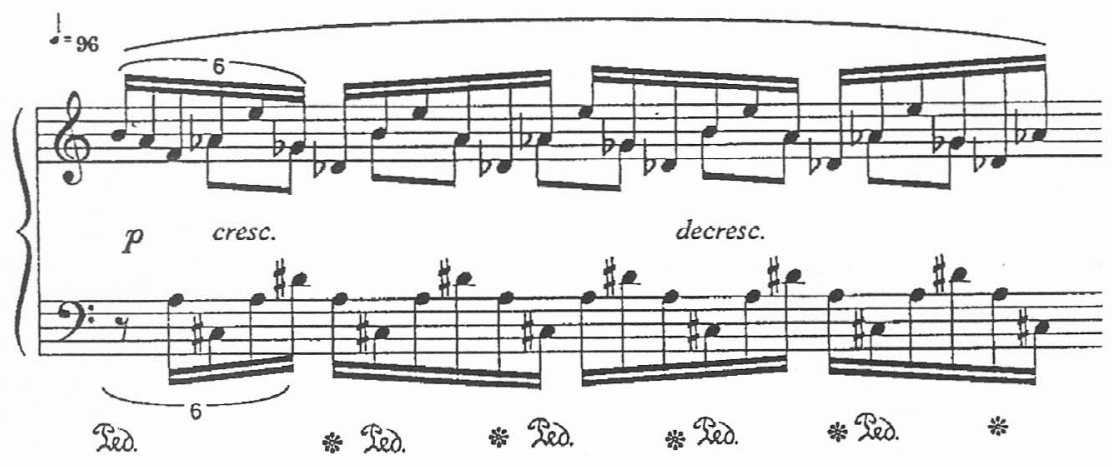

À parte dos elementos tomados do romantismo, Gilberto Mendes também utiliza procedimentos impressionistas, tais como o uso de harmonia quartal e escala de tons inteiros (como no material melódico do primeiro motivo, ex. 15) e, mais obviamente, em uma citação dos Jardins sous la pluie de Debussy (exemplos 22 e 23).

Exemplo 22. Claude Debussy - Jardins sous la pluie (compassos 1-2).

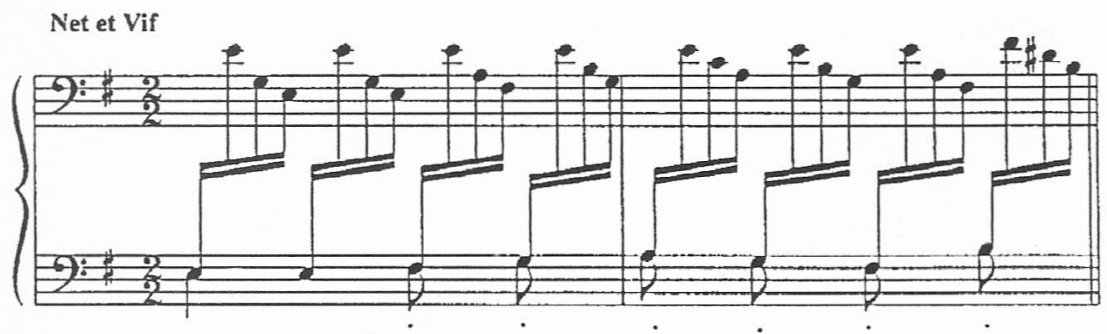

Exemplo 23. Gilberto Mendes - Vento Noroeste: motivo secundário (página 17).

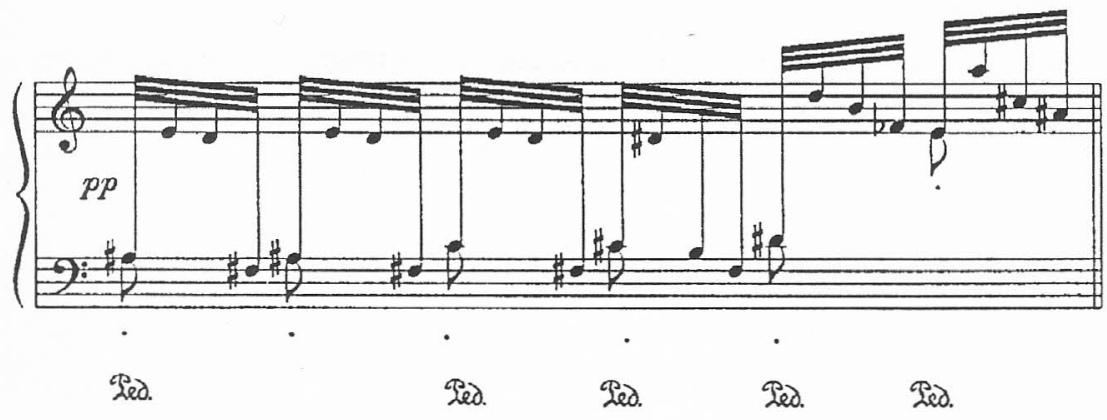


Conforme mencionado acima, a principal ferramenta para a integração dessas várias citações na obra é o uso do agregado de doze tons. A maioria dos motivos é conectada através de agregados comuns, conferindo à peça um senso de continuidade. Há trinta e nove grupos de agregados em Vento Noroeste, sendo a exposição de muitos deles pontuada por pausas. Além disso, os agregados não só conectam motivos aparentemente díspares, mas também funcionam como elementos estruturadores da peça. Assim, Vento Noroeste pode ser dividido em três seções que formam um padrão de expansão, onde o primeiro bloco contém seis agregados, o segundo contém catorze e o terceiro bloco contém dezenove agregados.

Após análise detalhada dos motivos presentes nestes três blocos, chega-se à conclusão de que a peça está dividida em um esquema $\mathrm{ABA}^{\prime}$, com alguns procedimentos típicos da forma sonata. Por exemplo, há motivos da seção A que são recapitulados (ainda que em ordem inversa) na seção $A^{\prime}$. Na seção $B$ podemos encontrar trechos onde determinados motivos secundários são desenvolvidos. Obviamente, o uso que o compositor faz desse esquema formal é bastante livre, não havendo intenção de reproduzir os padrões clássicos de estruturação.

Há dois motivos principais na parte inicial de Vento Noroeste: após uma curta introdução, o primeiro (I) - baseado, como vimos, em um Estudo de Chopin (exemplos 4 e 15) - é exposto e gradualmente transformado, tornando-se uma figura de acompanhamento à qual são superpostos acordes. Nesta nova versão, o motivo é fragmentado e interpolado com dois motivos secundários, que se constituem de material original. O segundo motivo principal (II) tampouco se baseia em citação e suas características melódicas fazem-no soar como um tema propriamente dito. A passagem tem um centro tonal claro (Lá menor) e um caráter repetitivo pronunciado: o tema se faz ouvir por nove vezes, sendo expandido nas repetições (exemplo 24 na paágina seguinte). 
Exemplo 24. Gilberto Mendes - Vento Noroeste: motivo II após expansão gradual (página 6).

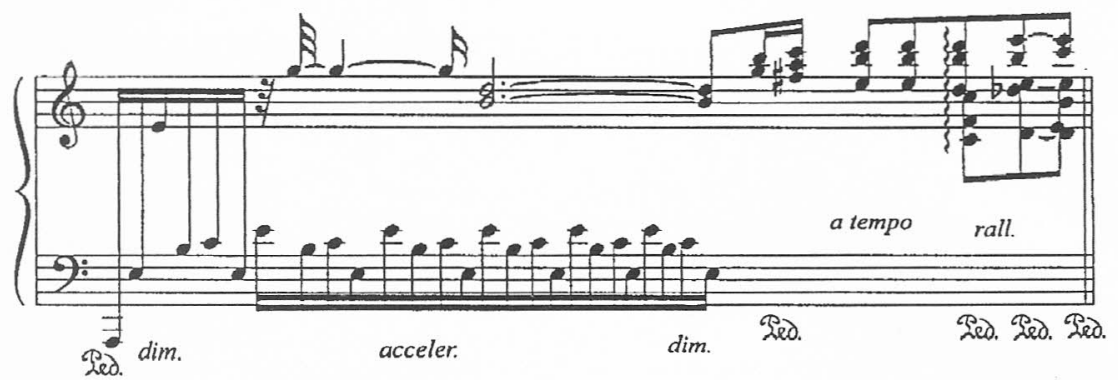

Após o que poderia ser considerado uma codetta (ex. 25), a seção B inicia-se com a apresentação de um novo motivo (III), também baseado em Estudo de Chopin (exs. 16 e 17). Este motivo tem uma importância estrutural considerável, já que abre e fecha a parte intermediária da peça.

Exemplo 25. Gilberto Mendes - Vento Noroeste: codetta (páginas 6-7).

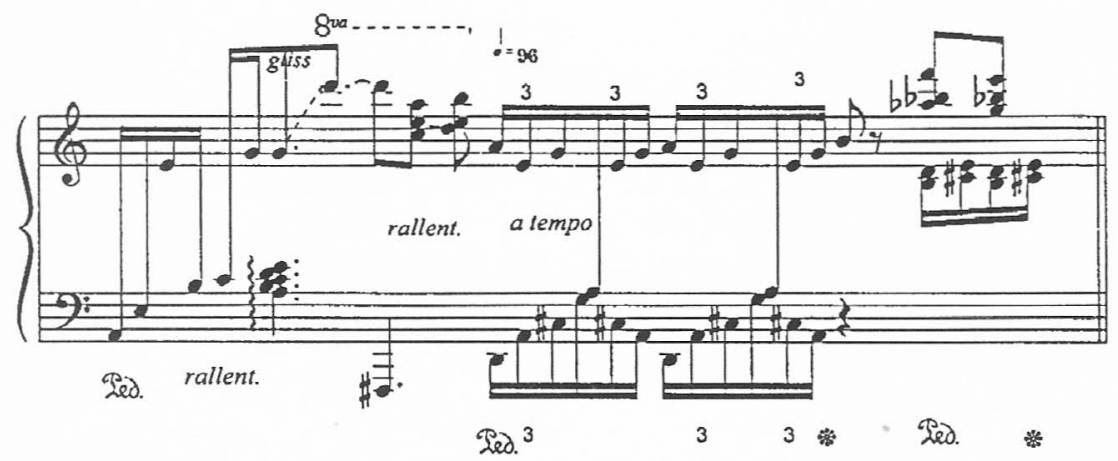

Como foi dito, esta seção apresenta procedimentos com caráter de desenvolvimento, já que alguns motivos da seção A são apresentados expandidos, enquanto outros aparecem em versão fragmentada. No bloco final de Vento Noroeste (A'), a recorrência dos motivos da primeira seção constitui um claro indício de recapitulação. Nesta, os motivos I e II são apresentados em sua forma expandida com a ordem de aparição invertida. Uma espécie de coda começa com a repetição literal da introdução, seguida de mais um enunciado dos dois motivos (I e II) da seção A. Desta vez, as terças do primeiro motivo (I) são ouvidas em semitons 
(ao invés dos tons inteiros iniciais), enquanto o segundo motivo (II) reaparece comprimido, com o glissando levando à última aparição das terças (I), concluindo a peça de maneira serena.

Conforme mencionamos, Vento Noroeste foi composta em um período que representa o retorno de Gilberto Mendes à música instrumental e o seu gradual afastamento da vanguarda mais radical, típica das obras corais. As reações a esta guinada estilística não estariam isentas do caráter polêmico, já habitual na biografia do compositor.

Enio Squeff traduziria esta surpresa ao comentar a primeira audição de uma peça do mesmo período, o Concerto para Piano e Orquestra (1981): "Desconfio em princípio desta nova composição de Gilberto Mendes; ela me agradou demais a uma primeira audição"4. Esta reação só se justifica pelo desconhecimento, na época, das obras instrumentais dos anos de formação do compositor. Após um estudo mais aprofundado, podemos constatar como as obras da maturidade são fruto da evolução de uma linguagem própria, que foi urdida já a partir dos seus primeiros ensaios criativos.

\section{Conclusão}

Ao compararmos o Allegro da Sonatina Mozartiana - composto em um período de formação técnica e estética - com Vento Noroeste - da maturidade de Gilberto Mendes -, damo-nos conta do avanço obtido pelo compositor na consolidação de seu estilo ímpar. Ao esquema formal convencional da Sonatina (resultado da emulação consciente de modelo mozartiano), contrapõe-se a originalidade do tratamento dado à forma sonata em Vento Noroeste. O uso de blocos repetitivos também demonstra uma significativa evolução (comparar os exemplos 13 e 24). No entanto, é ao considerar a manipulação da citação musical que podemos apreciar plenamente a maturidade alcançada pelo compositor.

Enquanto na Sonatina Mendes utiliza um só modelo (com exceção da pequena "intromissão" da Invenção de Bach [exemplo 12]), em Vento Noroeste tem-se uma verdadeira enciclopédia de figurações românticas e impressionistas. Além disso, a profusão de informações colhidas

4. Mendes, Uma Odisséia Musical, p. 192. 
de fontes secundárias não se restringe, nesta última obra, às texturas e figurações rítmicas. Há também o uso de determinadas escalas (caso dos tons inteiros presentes no motivo I) e intervalos (uso de harmonias quartais) que, combinados com os gestos colhidos do pianismo romântico, dão à peça uma simultaneidade de significados bastante complexa. Considerando-se esta abundância de elementos tomados de obras consagradas do repertório pianístico, o fato de Vento Noroeste não soar como um pot-pourri só pode ser atribuído ao domínio técnico atingido pelo compositor.

Embora Gilberto Mendes tenha iniciado o uso da citação musical por razões práticas (as peças consagradas do repertório serviram, como vimos, de guia ao jovem autodidata), os experimentos continuados com esta técnica através de diferentes períodos criativos propiciaram-lhe a evolução de uma linguagem sem precedentes na música brasileira. Em Vento Noroeste, o compositor vai além da paródia bem-humorada da Sonatina; nesta fase de maturidade artística, o uso de citações tem um efeito quase metalingüístico, a peça para piano parece "discutir" o próprio repertório do instrumento.

Vista como oápice de um processo de experimentação que começa em seus anos de formação, Vento Noroeste, ao mesclar estéticas aparentemente opostas, não se encaixa nos cânones técnicos e estéticos que têm norteado a produção musical brasileira neste século. Este caráter verdadeiramente revolucionário da obra de Gilberto Mendes tem, infelizmente, passado desapercebido pela maioria dos críticos e estudiosos. $O$ respeito invulgar que o compositor tem demonstrado às criações musicais de todos os tempos é refletido de maneira direta na sua produção pianística, saturada de expressividade e procedimentos singulares. A tentativa de reconciliação do presente e do passado, através do questionamento e manipulação da dialética criação/apropriação, coloca a produção instrumental de Gilberto Mendes em lugar à parte no cenário musical contemporâneo.

\section{Bibliografia}

Bezerra, Márcio Antonio Salvador. A Unique Brazilian Composer: A Study of the Music of Gilberto Mendes Through Selected Piano Pieces. Tese (Doutorado) - University of Arizona, 1998. 
Caldeira Filho, João. "Ginastera e Futebol no Municipal." O Estado de São Paulo, 26 de julho de 1974.

Ellmerich, Luis. " 'Vale Tudo' no Municipal." Diário de São Paulo, 18 de novembro de 1965.

Martins, José Eduardo. "Gilberto Mendes." Estudos Avançados 5, no 13 (SetembroDezembro de 1991), pp. 196-197.

"Movimento Música Nova: Em Busca da Modernidade." Caderno de Música 8 (dez. 1981), pp. 4-6.

Mendes, Gilberto. "Musica Nuova Brasiliana: Dati e Problemi." Aut Aut, pp. 109-110 (março 1969), pp. 206-212.

.Uma Odisséia Musical: dos Mares do Sul à Elegância Pop/Art Déco. São Paulo: Editora da Universidade de São Paulo e Editora Giordano, 1994.

Mounsey, Paul. "Music in Brazil: Willy Corrêa de Oliveira and Gilberto Mendes." Contact Magazine 31 (Outono 1987), pp. 21-26.

Neves, José Maria. Música Contemporânea Brasileira. São Paulo, Ricordi Brasileira, 1981.

Oliveira, Willy Corrêa de. "Gilberto Mendes, Compositor Santista, em Várias Peças." A Tribuna (Santos), 2 de outubro de 1960.

PARDEY, Wolfgang. "Mit bestechender Virtuosität." Lübecker Nachrichten, 29 de maio de 1988.

Ross, James. "Brazilian Pianist Impeccable." Miami Herald, 25 de junho de 1982.

Santos, Antonio Eduardo. "O Antropofagismo" na Obra Pianística de Gilberto Mendes. Dissertação (Mestrado) - Universidade Estadual Paulista "Júlio de Mesquita Filho", 1995. 